Original Research Paper

\title{
Effects of Curing Temperature and MMA Content on the Working Life of MMA-Modified Vinyl Ester Polymer Concrete
}

\author{
${ }^{1}$ Ki-Bong Choi, ${ }^{2}$ Seung-Ho Min and ${ }^{3}$ Kyu-Seok Yeon \\ ${ }^{1}$ Department of Architectural Engineering, Gachon University, Seongnam, Gyeonggi-do, South Korea \\ ${ }^{2}$ Building Projects Operation Division, GS E\&C, Seongnam, Gyeonggi-do, South Korea \\ ${ }^{3}$ Department of Regional Infrastructure Engineering, Kangwon National University, Chuncheon, South Korea
}

Article history
Received: 7-06-2016
Revised: 21-10-2016
Accepted: 24-10-2016
Corresponding Author:
Kyu-Seok Yeon
Department of Regional
Infrastructure Engineering,
Kangwon National University,
Chuncheon,Gangwon-do, South
Korea, Phone \& Fax: +82-33-
250-6465
Email: ksyeon@kangwon.ac.kr

\section{Introduction}

Polymer concrete is a sort of polymer-concrete composite material made by fully replacing the cementitious binder of conventional concrete with a polymeric binder. Due to such nature, various material properties such as strength, adhesion, water tightness, chemical resistance, freeze-thaw resistance and abrasion resistance of polymer concrete are generally improved to a great extent in comparison with ordinary Portland cement concrete (Chandra and Ohama, 1994). However, it is recognized that polymer concrete also has some limitations originated from high cost of polymer resins, large shrinkage developed during hardening process and large thermal volume changes. To resolve these issues, many studies are underway to enhance the binder characteristics and to develop shrinkage reducing agents and a new type of resins (Fowler, 1989).

Thermosetting resins including unsaturated polyester, epoxy, acrylic and vinyl ester are popularly used for manufacturing polymer concrete, whose physical and mechanical properties are substantially different from one another depending on the type of the binder used (Haddad et al., 1983; Hyun and Yeon, 2012; Ohama, 1973). A vinyl ester resin employed in this study is known to have excellent chemical and corrosion resistance coupled with outstanding heat performance, which makes the vinyl ester resin a good choice for practical applications such as in swimming pools, sewer pipes and solvent storage tanks (Caoand and Lee, 2003; Cook et al., 1997).

In general, the setting time of polymer concrete is significantly shorter than that of cement concrete. Owing to such short setting time, the use of polymer concrete can markedly reduce the curing time of cast-in-place components and improve the productivity of precast products-typically, formworks can be stripped within about 1 to 3 hours after placement. Accordingly, formworks can be reused for manufacturing precast products in factories, leading to labor saving in field applications (Chandra and Ohama, 1994); therefore, determination of polymer concrete's working life is an 
utmost important factor for both precast and cast in place applications (Ohama, 1978) as it helps in scheduling various stages involved in construction operations such as transporting, placing, compacting and finishing of concrete (Brooks et al., 2000).

This study used a vinyl ester resin modified by MMA monomer as a binder (hereinafter "MMA-modified vinyl ester polymer concrete") so as to improve the workability and reduce the setting shrinkage. The working life of polymer concrete at ambient temperature can be widely controlled by selecting suitable initiators, promoters, hardeners and water/binder ratios, all of which are well known influencing factors. Accordingly, in this study, a focus is placed on the effects of curing temperature and MMA content on the working life of MMA-modified vinyl ester polymer concrete.

\section{Experimental Program}

\section{Materials}

\section{Binder}

This study used a bisphenolA epoxy-based vinyl ester as a resin for polymer concrete. The bisphenol A epoxybased vinyl ester resin had a density of 1.2 (at $25^{\circ} \mathrm{C}$ ), a viscosity of $250 \mathrm{mPa} \cdot \mathrm{s}\left(\right.$ at $20^{\circ} \mathrm{C}$ ), a vapor density of 3.6 and a styrene content of 45 wt.\%. As a monomer, the present study employed a methyl methacrylate (MMA) monomer, which was produced by esterifying methacrylic acid with methanol. The MMA used in this study was a transparent liquid with a density of 0.942 (at $25^{\circ} \mathrm{C}$ ), a viscosity of $0.56 \mathrm{mPa} \cdot \mathrm{s}$ (at $20^{\circ} \mathrm{C}$ ) and a molecular weight of $100 \mathrm{~g} / \mathrm{mol}$. As an initiator for the vinyl ester resin, a $45 \% \quad N, N$-dimethyl- $p$-toluidine (DMP)solution with 55\% methyl ethyl ketone peroxide (MEKPO) was employed, whose specific gravity is 1.12 (at $25^{\circ} \mathrm{C}$ ). To initiate the reaction between the vinyl ester resin and MMA monomer, a promotor should be added. This study used a cobalt naphthenate as a promotor as it allows polymerization even both at room and low temperatures. The cobalt naphthenate used in this study was a violet liquid with a density of $0.95\left(\right.$ at $25^{\circ} \mathrm{C}$ ) and a boiling temperature of $110.6^{\circ} \mathrm{C}$.

\section{Aggregate and Filler}

This study used silica sand as aggregates. Figure 1 and Table 1 show the gradation curve with the upper and lower gradation limits specified in ASTM C33 and physical properties of the silica sand used in this study, respectively. In addition, this study adopted a ground calcium carbonate powder as filler. The physical properties and chemical components of the filler are presented in Tables 2 and 3, respectively.

Table 1. Physical properties of aggregate

\begin{tabular}{lllllll}
\hline Size $(\mathrm{mm})$ & $\begin{array}{l}\text { Apparent specific } \\
\text { gravity }(-)\end{array}$ & $\begin{array}{l}\text { Bulk specific } \\
\text { gravity }(-)\end{array}$ & $\begin{array}{l}\text { Unit weight } \\
\left(\mathrm{kg} / \mathrm{m}^{3}\right)\end{array}$ & $\begin{array}{l}\text { Fineness } \\
\text { modulus }(-)\end{array}$ & $\begin{array}{l}\text { Water } \\
\text { content }(\%)\end{array}$ & $\begin{array}{l}\text { Organic } \\
\text { impurities }\end{array}$ \\
\hline $0.08-8$ & 2.64 & 2.62 & 1,648 & 3.09 & $<0.1$ & Nil \\
\hline
\end{tabular}

Table 2. Properties of ground calcium carbonate

\begin{tabular}{llllll}
\hline Specific & Absorption & Water content & & Mean grain & Retained percentage \\
\hline gravity & $(\mathrm{cc} / \mathrm{gr})$ & $(\%)$ & $\mathrm{pH}$ & size $(\mu \mathrm{m})$ & of 325 mesh sieve \\
0.75 & 0.20 & $\leq 0.3$ & 8.8 & 13 & 0.03 \\
\hline
\end{tabular}

Table 3. Chemical component of ground calcium carbonate (unit: \%)

\begin{tabular}{llllll}
\hline $\mathrm{CaO}$ & $\mathrm{Al}_{2} \mathrm{O}_{3}$ & $\mathrm{Fe}_{2} \mathrm{O}_{3}$ & $\mathrm{SiO}_{2}$ & $\mathrm{MgO}$ & Loss on ignition \\
\hline 53.7 & 0.25 & 0.09 & 2.23 & 0.66 & 42.4 \\
\hline
\end{tabular}

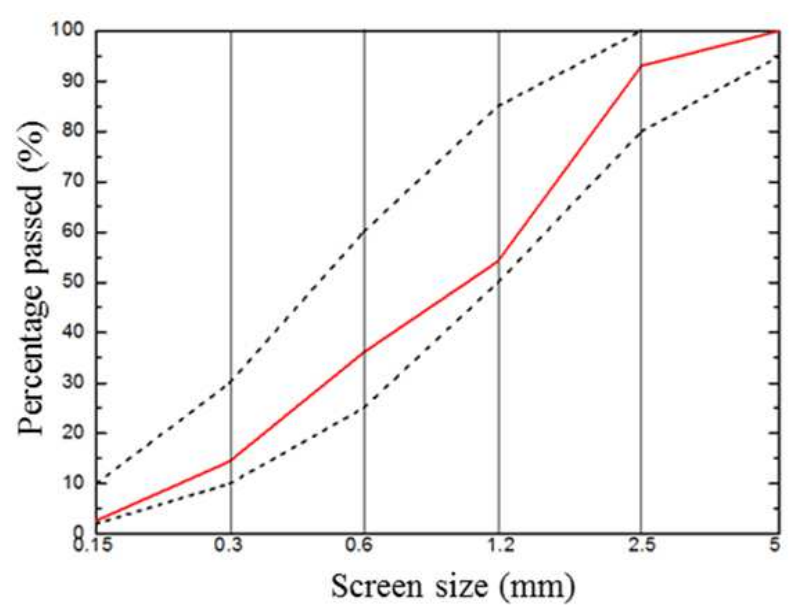

Fig. 1. Gradation curve of aggregate with upper and lower limits 


\section{Methods}

\section{Determination of Mixture Proportions}

In this study, optimum mixture proportions were selected based on a series of trial tests on slump flow and strength. The mixture proportions were designed to have pa maximum portion of aggregate phases with a minimum portion of polymeric binders. The binder formations and mixture proportions of the polymer concrete used are presented in Table 4.

\section{Setting Time Measurement}

This study determined the setting time of the binder based on ASTM D 2471 (Standard test method for gel time and peak exothermic temperature of reacting thermosetting resin), which measures the time duration right after adding an initiator into a polymeric resin until it reaches a peak exothermic temperature. For the temperature measurement over time, a data logger (Tokyo Sokki; TDS-602) with a T-type thermocouple was used.

\section{Working Life Measurement}

In this study, the finger-touching method (Ohama, 1978) as per PC-4 (Determining methods for working life of fresh polymer concrete and mortar) in RILEM TC 113CPT was used to determine the polymer concrete's working life. The total time elapsed from initiator addition to caking (or gelling) was defined as the working life of polymer concrete. The caking time was estimated by the finger touching method specified in RILEM TC-CPT 1995 (PC-4 Determining methods for working life of fresh polymerconcrete and mortar) once the fresh polymer concrete sample was placed in a plastic bag.

\section{Results and Discussion}

\section{Setting Time of Vinyl Ester Polymeric Binder}

The setting time of vinyl ester polymeric binder with different curing temperatures, MMA contents and concentrations of initiator and promoter was measured and the results are presented in Table 5. It was found that the setting time ranged from 50-315, 23-131, 21-70 and 14-45 $\mathrm{min}$ when the curing temperature was $-10,0,10$ and $20^{\circ} \mathrm{C}$, respectively. When the concentration of MEKPO was $1.0,1.5$ and $2.0 \mathrm{phr}$, the setting time was found to be 20-315, 16-253 and 14-218 $\mathrm{min}$, respectively. Also noted was that the setting time varied between 20 and 315, 17 and 195 and 14 and $92 \mathrm{~min}$ when the concentration of cobalt naphthenate was 1.0, 1.5 and $2.0 \mathrm{phr}$, respectively. In addition, the MMA content affected the setting time of MMA-modified vinyl ester polymer concrete; the setting time tended to vary within the range of 14-249 $\mathrm{min}, 22-285 \mathrm{~min}$ and 25-315 min for MMA contents of $0,2.5$ and 5.0 wt.\%, respectively. Based on the results obtained, it can be concluded that the setting time of the vinyl ester polymeric binder was shortened as the concentration of initiator and promoter and the curing temperature increased whereas the setting time was delayed with an increase in MMA content. Among these factors, the curing temperature and the concentration of cobalt napthenate had more significant effects in reducing the setting time than the others factors, which is similar to the results of a previous study (Ohama, 1978); the concentration of initiator and promoter had a substantial effect on the reduction of polymer's gel time.

Generally, when polymer concrete is selected for cast-in-place or precast applications, a setting time of at least one hour is required to complete finishing jobs. Based on the obtained experimental data in this study, polymeric binders that can set within 1 hour even at $10^{\circ} \mathrm{C}$ curing temperature were achieved when the MEKPO and cobalt naphthenate concentration was 2.0 phr each. Thus, the variations in MMA-modified vinyl ester polymeric binder's setting time with different curing temperatures $\left(-10,0,10\right.$ and $\left.20^{\circ} \mathrm{C}\right)$ and MMA contents $(0,2.5$ and $5.0 \mathrm{wt} . \%)$ were investigated while fixing the concentration of MEKPO and cobalt naphthenate at $2.0 \mathrm{phr}$. Table 6 shows the data extracted from Table 5, which was constructed to investigate the effects of curing temperature and MMA content on the setting time of vinyl ester polymeric binder (the concentrations of initiator and promoter were $2 \mathrm{phr}$ each). Also, Figs. 2, 3 and 4 present the variations of the polymeric binder's setting time for different curing temperatures and MMA contents derived based on Table 6. As shown in Fig. 2, the setting time of polymeric binder was shortened with an increased curing temperature. Figure 3 demonstrates that the setting time was delayed with an increased MMA content but its effect was less significant than curing temperature. Figure 4 shows a three-dimensional plot showing the effects of these two factors on the binder's setting time. The results show that the setting time of polymeric binder becomes greater as the curing temperature decreased and the MMA content increased.

\section{Working Life of Vinyl Ester Polymer Concrete}

MMA-modified vinyl ester polymer concrete's working life was measured by fixing the concentrations of initiator and promoter at $2 \mathrm{phr}$ while gradually changing the curing temperature and MMA content and the results are shown in Table 7 and Figs. 5, 6 and 7. According to the results, the working life was significantly shortened with an increased curing temperature: $120-135 \mathrm{~min}$ at $-10^{\circ} \mathrm{C}, 39-94 \mathrm{~min}$ at $0^{\circ} \mathrm{C}, 24-44 \mathrm{~min}$ at $10^{\circ} \mathrm{C}$ and $20-38 \mathrm{~min}$ at $20^{\circ} \mathrm{C}$. However, the working life was delayed but not much changed with an increased MMA content: 20-120, 30126 and 38-135 min for the MMA contents of $0,2.5$ and $5.0 \mathrm{wt} . \%$, respectively. 
Ki-Bong Choi et al. / American Journal of Applied Sciences 2017, 14 (1): 141.149 DOI: 10.3844/ajassp.2017.141.149

Table 4. Binder formation and mixture proportions of polymer concrete

\begin{tabular}{|c|c|c|c|c|c|}
\hline \multirow[b]{2}{*}{ Binder content (wt.\%) } & \multicolumn{5}{|l|}{ Binder formation } \\
\hline & VE: MMA (wt.\%) & $\operatorname{MEKPO~(phr*)~}$ & Cobalt naphthenate (phr) & Filler (wt.\%) & Aggregate (wt.\%) \\
\hline 12.0 & 100: 0 & 2 & 2 & 18.00 & 70.00 \\
\hline 11.5 & $97.5: 2.5$ & & & 17.25 & 71.25 \\
\hline 11.0 & $95.0: 5.0$ & & & 16.50 & 72.50 \\
\hline
\end{tabular}

"*arts per hundred parts of resin

Table 5. Setting time of vinyl ester polymeric binder for different curing temperatures, MEKPO concentration, cobalt naphthenate concentration, and MMA contents (unit: $\min$ )

\begin{tabular}{|c|c|c|c|c|c|}
\hline \multirow[b]{2}{*}{ Curing temperature $\left({ }^{\circ} \mathrm{C}\right)$} & \multirow[b]{2}{*}{ MEKPO (phr $\left.{ }^{*}\right)$} & \multirow[b]{2}{*}{ Cobalt naphthenate $\left(\mathrm{phr}^{*}\right)$} & \multicolumn{3}{|c|}{ MMA content (wt.\%) } \\
\hline & & & 0 & 2.5 & 5.0 \\
\hline \multirow[t]{9}{*}{-10} & 1.0 & 1.0 & 249 & 285 & 315 \\
\hline & & 1.5 & 139 & 185 & 195 \\
\hline & & 2.0 & 76 & 87 & 92 \\
\hline & 1.5 & 1.0 & 215 & 235 & 253 \\
\hline & & 1.5 & 109 & 135 & 167 \\
\hline & & 2.0 & 69 & 82 & 89 \\
\hline & 2.0 & 1.0 & 188 & 195 & 218 \\
\hline & & 1.5 & 86 & 89 & 101 \\
\hline & & 2.0 & 50 & 53 & 77 \\
\hline \multirow[t]{9}{*}{0} & 1.0 & 1.0 & 104 & 117 & 131 \\
\hline & & 1.5 & 53 & 74 & 84 \\
\hline & & 2.0 & 31 & 35 & 59 \\
\hline & 1.5 & 1.0 & 69 & 80 & 96 \\
\hline & & 1.5 & 43 & 53 & 71 \\
\hline & & 2.0 & 29 & 45 & 57 \\
\hline & 2.0 & 1.0 & 54 & 64 & 80 \\
\hline & & 1.5 & 28 & 47 & 63 \\
\hline & & 2.0 & 23 & 35 & 48 \\
\hline \multirow{9}{*}{10} & 1.0 & 1.0 & 47 & 58 & 70 \\
\hline & & 1.5 & 33 & 53 & 59 \\
\hline & & 2.0 & 28 & 29 & 33 \\
\hline & 1.5 & 1.0 & 34 & 43 & 47 \\
\hline & & 1.5 & 26 & 32 & 38 \\
\hline & & 2.0 & 19 & 29 & 33 \\
\hline & 2.0 & 1.0 & 28 & 43 & 45 \\
\hline & & 1.5 & 22 & 32 & 36 \\
\hline & & 2.0 & 21 & 29 & 32 \\
\hline \multirow[t]{9}{*}{20} & 1.0 & 1.0 & 29 & 36 & 45 \\
\hline & & 1.5 & 26 & 27 & 39 \\
\hline & & 2.0 & 20 & 24 & 30 \\
\hline & 1.5 & 1.0 & 21 & 29 & 36 \\
\hline & & 1.5 & 20 & 24 & 27 \\
\hline & & 2.0 & 16 & 23 & 26 \\
\hline & 2.0 & 1.0 & 20 & 26 & 29 \\
\hline & & 1.5 & 17 & 24 & 26 \\
\hline & & 2.0 & 14 & 22 & 25 \\
\hline
\end{tabular}

" parts per hundred parts of resin

Table 6. Setting time of vinyl ester polymeric binder for different MMA contents and curing temperatures when concentrations of MEKPO and cobalt naphthenate were 2 phr each(unit: min)

\begin{tabular}{llll}
\hline & MMA content $(w t . \%)$ & & \\
Curing temperature $\left({ }^{\circ} \mathrm{C}\right)$ & 0 & 2.5 & 5.0 \\
\hline-10 & 0 & 53 & 77 \\
0 & 23 & 35 & 48 \\
10 & 21 & 29 & 32 \\
20 & 14 & 22 & 25 \\
\hline
\end{tabular}




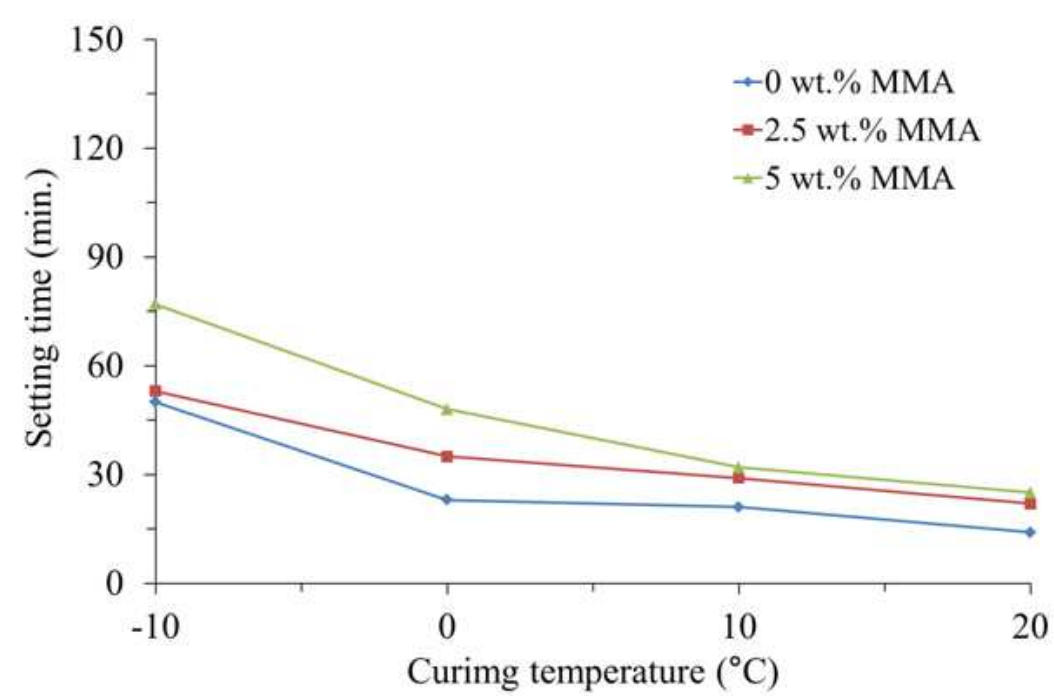

Fig. 2. Effect of curing temperature on setting time of vinyl ester polymeric binder

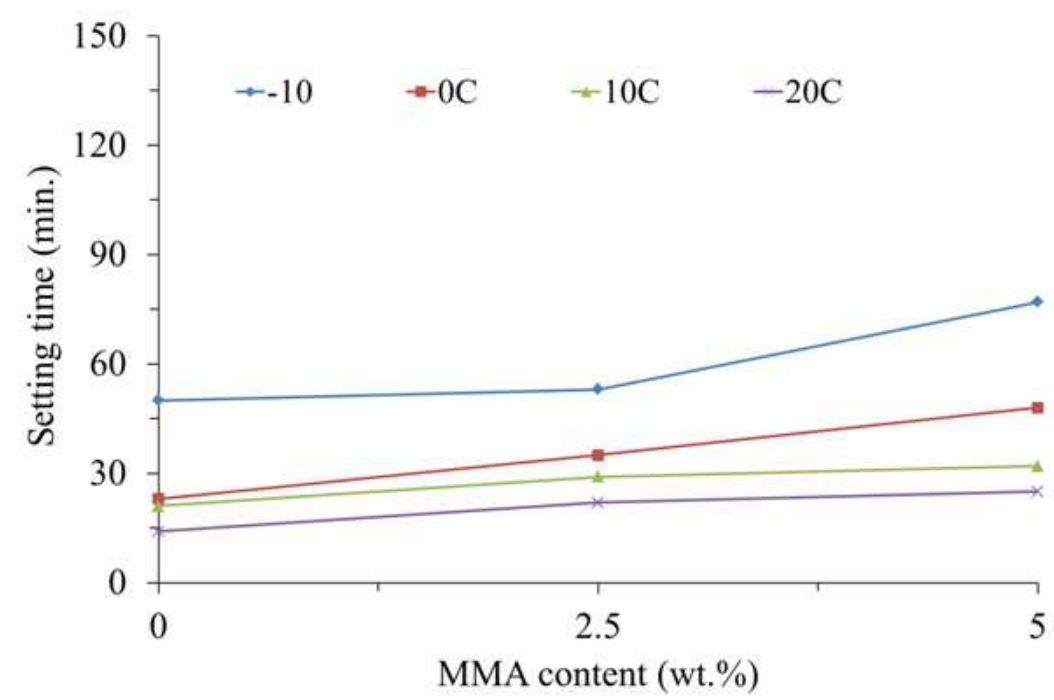

Fig. 3. Effect of MMA content on setting time of vinyl ester polymeric binder

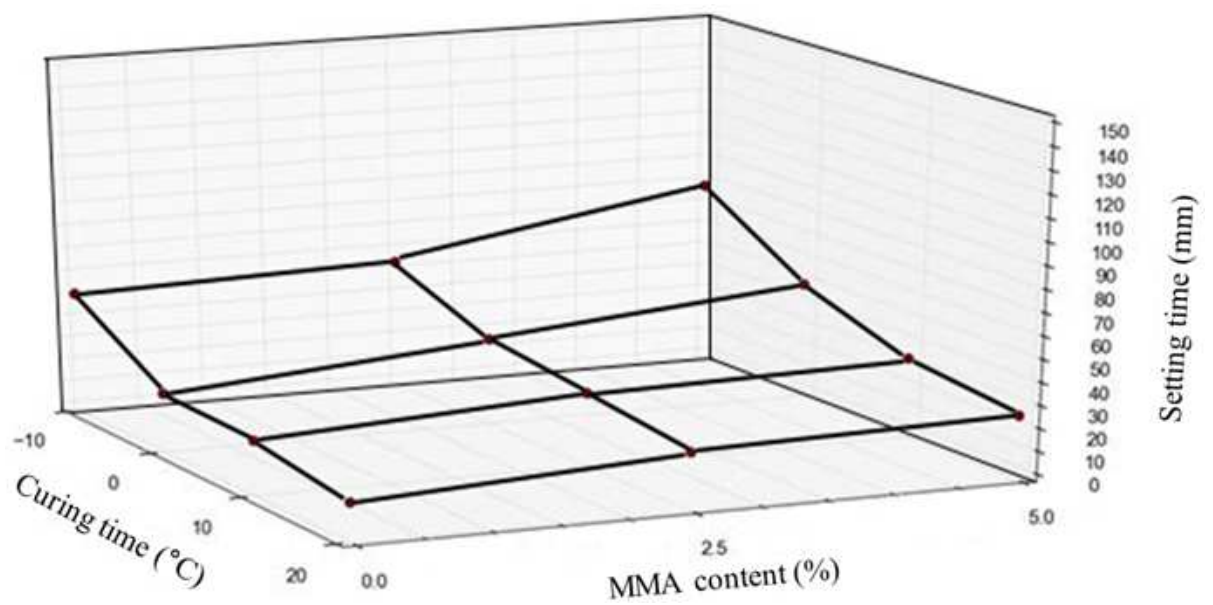

Fig. 4. Effects of MMA content and curing temperature on setting time of vinyl ester polymeric binder 


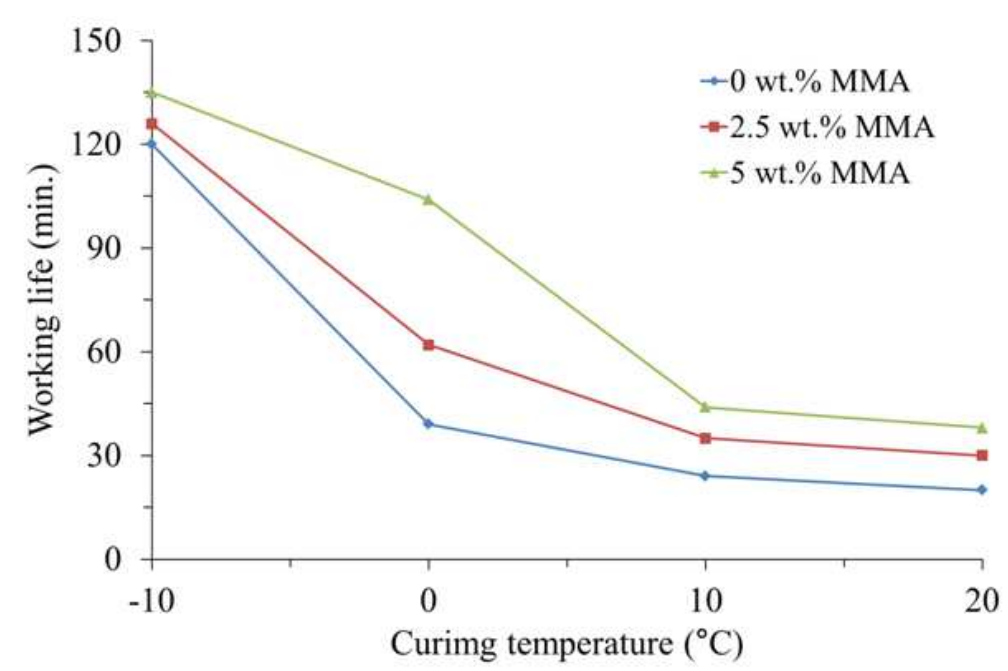

Fig. 5. Effect of curing temperature on working life of vinyl ester polymer concrete

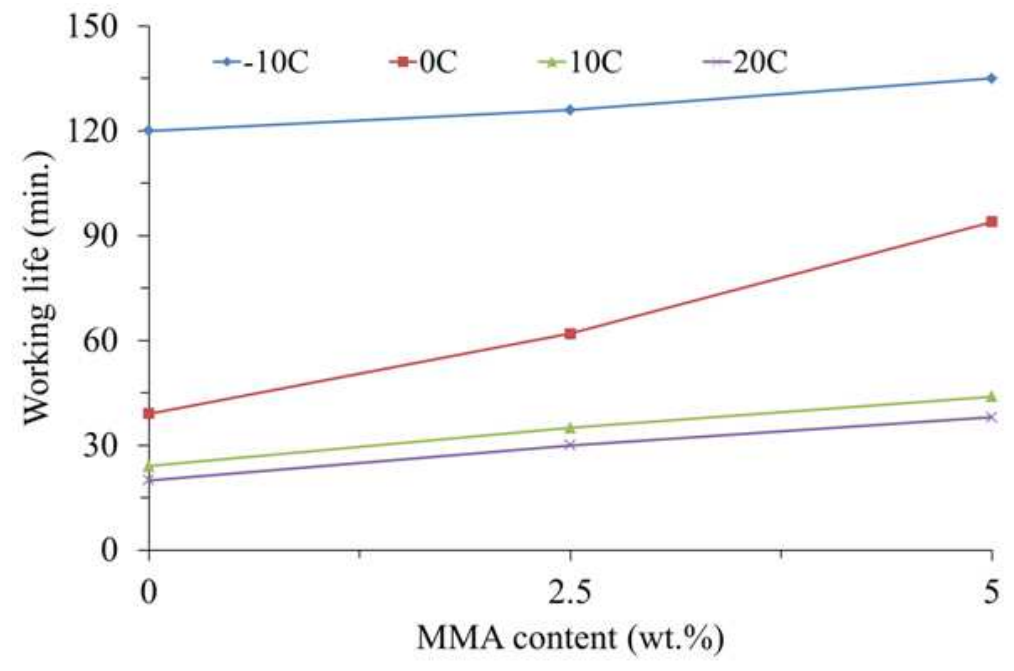

Fig. 6. Effect of MMA content on working life of vinyl ester polymer concrete

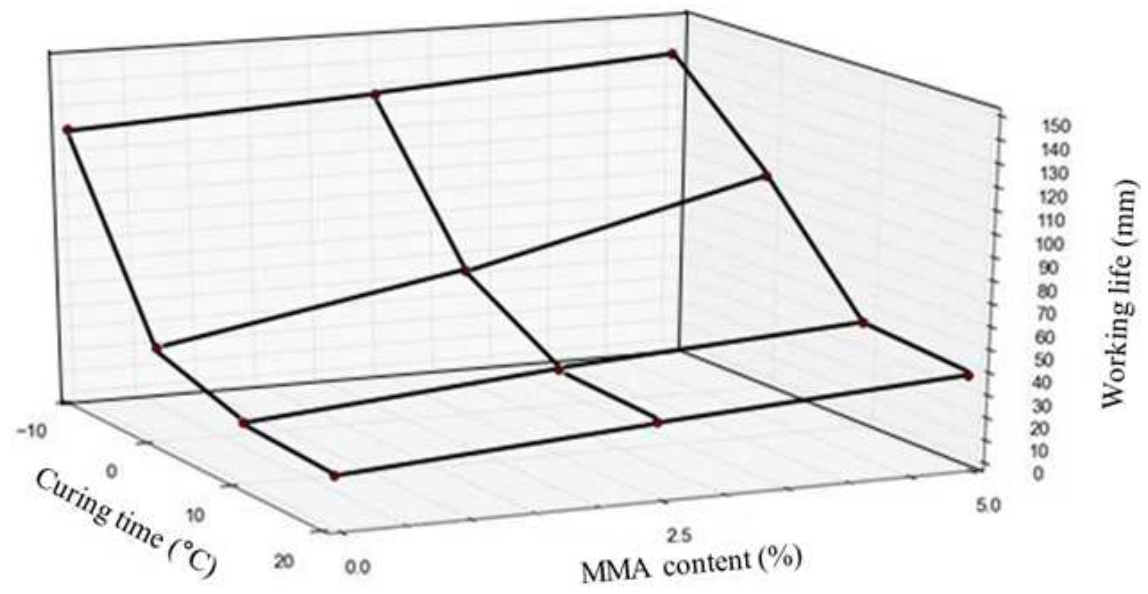

Fig. 7. Effects of MMA content and curing temperature on working life of vinyl ester polymer concrete 
When comparing the measured working life of vinyl ester polymer concrete with the setting time of vinyl ester polymeric binder, the working life was delayed as much as 70 and $13 \mathrm{~min}$ at curing temperatures of -10 and $20^{\circ} \mathrm{C}$, respectively. Also, the working life tended to increase as the MMA content increased, but the effect of MMA content was not as significant as that of curing temperature. The reason for the longer working life of polymer concrete than the setting time of polymeric binder is because the polymer concrete includes filler and aggregate up to 88-89 wt.\%, which results in wider spacing among the polymer molecules than those in pure polymeric binders.

The working life of vinyl ester polymer concrete tended to be reduced as the curing temperature became higher but was delayed with an increased MMA content. Between the factors, the curing temperature had a more pronounced influence on the working life of vinyl ester polymer concrete than the MMA content. The results obtained in this paper were similar to those of previous studies in that the initial and final setting time decreased for all types of polymer concrete as the curing temperature increased (Brooks et al., 2000) and the setting time of polymeric binder was largely dependent on the casting temperature (Ahn et al., 2009). In addition, the results from other previous studies in relation to the working life of polymer concrete reported that the working life of unsaturated polyester polymer concrete and MMA-polymethyl methacrylate (PMMA) polymer concrete was 15-90 (Ohama, 1978) and 13-63 min (Son and Yeon, 2012), respectively, at curing temperature of $20^{\circ} \mathrm{C}$. The working life of MMAmodified vinyl ester polymer concrete obtained from this study was $20-38 \mathrm{~min}$, which is much shorter than the working life of polyester polymer concrete and MMAPMMA polymer concrete, indicating that the use of
MMA-modified vinyl ester polymer concrete are beneficial in obtaining faster curing time and in turn, faster construction sequences in the field.

\section{Correlation between Setting Time of Vinyl Ester Binder and Working Life of Vinyl Ester Polymer Concrete}

Figure 8 shows the correlation between the setting time of vinyl ester resin and the working life of vinyl ester polymer concrete based on the data shown in Tables 6 and 7. A linear regression equation was derived to model their relationship as: $y=2.254 x-16.68$, in which $y$ is the working life of vinyl ester polymer concrete ( $\mathrm{min}$ ) and $x$ is the setting time of vinyl ester binder ( $\mathrm{min}$ ) with a coefficient of determination $R^{2}$ of 0.901 , indicating that the derived model is statistically quite confident. The results were coincided with the results of relevant previous studies (Ohama, 1978; Yeon et al., 2015; Yeon and Hyun, 2012) in that the setting time of the polymeric binder is closely associated with the working life of the polymer mortar/concrete and their relationship can be modeled using a linear regression equation. Therefore, it is quite feasible that the working life of vinyl ester polymer mortar or concrete can be estimated once the setting time of vinyl ester binder is measured. Table 8 summarizes the working life of MMA-modified vinyl ester polymer concrete estimated by the predictive developed in this study. The data can be useful to determine the concentration of initiator and promoter required for achieving the working life of MMA-modified vinyl ester polymer concrete given that the curing temperature and MMA content are fixed.

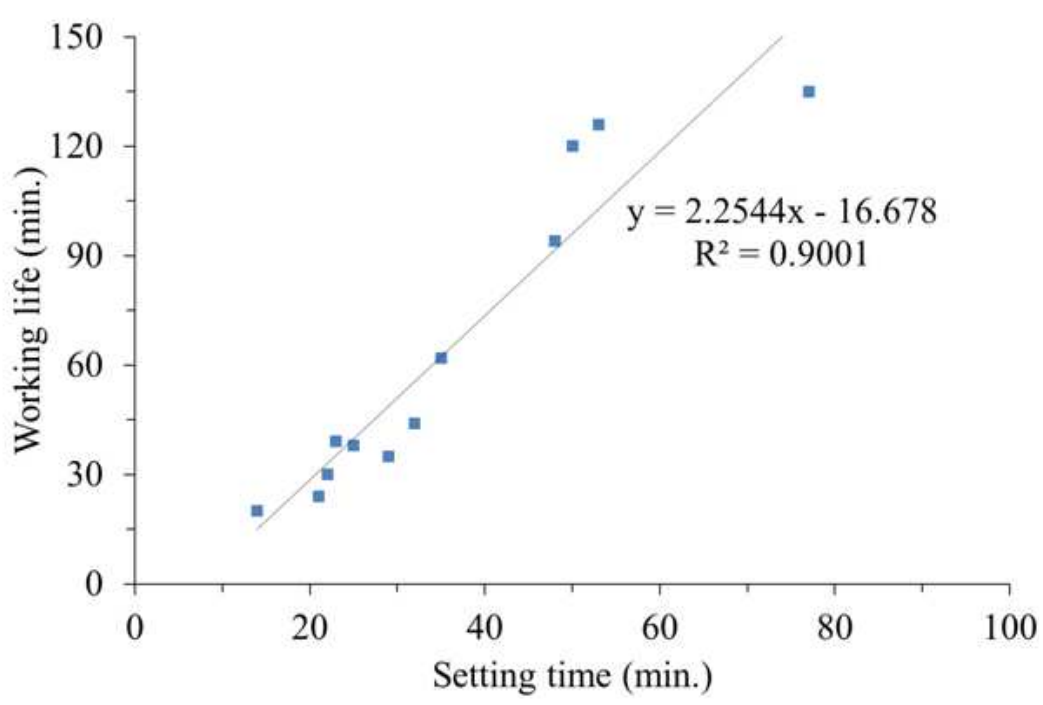

Fig. 8. Setting time of vinyl ester polymericbinder vs. working life of vinyl ester polymer concrete 
Table 7. Working life of vinyl ester polymer concrete for different MMA contents and curing temperatures when concentrations of MEKPO and cobalt naphthenate were $2 \mathrm{phr}$ each (unit: $\min$ )

\begin{tabular}{llll}
\hline & MMA content (wt.\%) & \\
Curing temperature $\left({ }^{\circ} \mathrm{C}\right)$ & - & 2.5 & 5.0 \\
\hline-10 & 0 & 126 & 135 \\
0 & 120 & 62 & 94 \\
10 & 39 & 35 & 44 \\
20 & 24 & 30 & 38 \\
\hline
\end{tabular}

Table 8. Working lifeofvinyl ester polymer concrete estimated by the equation developed in this study (unit: $\min$ )

\begin{tabular}{|c|c|c|c|c|c|}
\hline \multirow[b]{2}{*}{ Curing temperature $\left({ }^{\circ} \mathrm{C}\right)$} & \multirow[b]{2}{*}{$\operatorname{MEKPO~}\left(\mathrm{phr}^{*}\right)$} & \multirow[b]{2}{*}{ Cobalt naphthenate $\left(\mathrm{phr}^{*}\right)$} & \multicolumn{3}{|c|}{ MMA content (wt.\%) } \\
\hline & & & 0 & 2.5 & 5.0 \\
\hline \multirow{9}{*}{-10} & 1.0 & 1.0 & 544 & 625 & 693 \\
\hline & & 1.5 & 296 & 400 & 422 \\
\hline & & 2.0 & 154 & 179 & 190 \\
\hline & 1.5 & 1.0 & 468 & 513 & 553 \\
\hline & & 1.5 & 229 & 287 & 359 \\
\hline & & 2.0 & 138 & 168 & 183 \\
\hline & 2.0 & 1.0 & 407 & 422 & 474 \\
\hline & & 1.5 & 177 & 183 & 211 \\
\hline & & 2.0 & 96 & 102 & 156 \\
\hline \multirow[t]{9}{*}{0} & 1.0 & 1.0 & 217 & 247 & 278 \\
\hline & & 1.5 & 102 & 150 & 172 \\
\hline & & 2.0 & 53 & 62 & 116 \\
\hline & 1.5 & 1.0 & 138 & 163 & 199 \\
\hline & & 1.5 & 80 & 102 & 143 \\
\hline & & 2.0 & 48 & 84 & 111 \\
\hline & 2.0 & 1.0 & 105 & 127 & 163 \\
\hline & & 1.5 & 46 & 89 & 125 \\
\hline & & 2.0 & 35 & 62 & 91 \\
\hline \multirow[t]{9}{*}{10} & 1.0 & 1.0 & 89 & 114 & 141 \\
\hline & & 1.5 & 57 & 102 & 116 \\
\hline & & 2.0 & 46 & 48 & 57 \\
\hline & 1.5 & 1.0 & 59 & 80 & 89 \\
\hline & & 1.5 & 41 & 55 & 68 \\
\hline & & 2.0 & 26 & 48 & 57 \\
\hline & 2.0 & 1.0 & 46 & 80 & 84 \\
\hline & & 1.5 & 32 & 55 & 64 \\
\hline & & 2.0 & 30 & 48 & 55 \\
\hline \multirow[t]{9}{*}{20} & 1.0 & 1.0 & 48 & 64 & 84 \\
\hline & & 1.5 & 41 & 44 & 71 \\
\hline & & 2.0 & 28 & 37 & 50 \\
\hline & 1.5 & 1.0 & 30 & 48 & 64 \\
\hline & & 1.5 & 28 & 37 & 44 \\
\hline & & 2.0 & 19 & 35 & 41 \\
\hline & 2.0 & 1.0 & 28 & 41 & 48 \\
\hline & & 1.5 & 21 & 37 & 41 \\
\hline & & 2.0 & 14 & 32 & 39 \\
\hline
\end{tabular}

parts per hundred parts of resin

\section{Conclusion}

The purpose of this study was to investigate the effects of curing temperature and methyl methacrylate (MMA) content on working life of vinyl ester polymer concrete. The key findings of this research can be summarized as follows:

- The setting time of vinyl ester resin was reduced as the curing temperature and concentration of initiator and promoter increased, while it was delayed with an increased MMA content. Among these factors, the curing temperature and cobalt naphthenate concentration were found to have more significant effects on the setting time reduction

- The working life of vinyl esterpolymer concrete tended to decrease as the curing temperature increased, while it was delayed with an increased MMA content. Between these two factors, the curing temperature exhibiteda more significant influence on the working life of vinyl ester polymer concrete

- The working life of vinyl esterpolymer concrete was much longer than the setting time of polymeric binder. The difference between the working life and setting time tended to decrease with an increased curing temperature (about $70 \mathrm{~min}$ at $-10^{\circ} \mathrm{C}$ and 10 
min at $20^{\circ} \mathrm{C}$ ). The MMA content had a smaller effect than the curing temperature

- Aregression analysis performed between the vinyl ester resin's setting time and vinyl ester polymer concrete's working life yielded a linear equation of $y$ $=2.254 x-16.68$ with a coefficient of determination $R^{2}=0.901$, indicating that the obtained regression equation can be confidently used for predicting the working life of vinyl ester polymer concrete with a 11-12 wt.\% binder based on the setting time of vinyl ester resin

\section{Acknowledgements}

The author would like to express their gratitude to National Research Foundation (NRF) of Korea and the research teams at Kangwon National University and Gachon University, South Korea for their support in performing this research.

\section{Funding Information}

This work was supported by National Research Foundation of Korea (NRF) grant funded by the Korea government (MSIP) (No. NRF-2013R1A1A2009).

\section{Author's Contribution}

Ki-Bong Choi: Made substantial contributions to the experimental design, results discussions and final manuscript writing.

Seung-Ho Min: Performed the testing, data collection and data analysis.

Kyu-Seok Yeon: Managed the project as a principal investigator and drafted the manuscript.

\section{Ethics}

This article is original and unpublished elsewhere. The authors declare no conflict of interest in the development of the research and publication of this article.

\section{References}

Ahn, N., D.K. Park, J. Lee and M.K. Lee, 2009. Structural test of precast polymer concrete. J. Applied Polymer Science, 114: 1370-1376. DOI: 10.1002/app.30731

Brooks, J.J., M.A. Megat Johari and M. Mazloom, 2000. Effect of admixtures on the setting times of highstrength concrete. Cement Concrete Composites, 22: 293-301. DOI: 10.1016/S0958-9465(00)00025-1
Caoand, X. and L.J. Lee, 2003. Control of Shrinkage and final conversion of vinyl ester resins cured in lowtemperature molding processes. J. Applied Polymer Science, 90: 1486-1496. DOI: 10.1002/app.12649

Chandra, S. and Y. Ohama, 1994. Polymers in Concrete. CRC Press, Inc.

Cook, W.D., G.P. Simon, P.J. Burchill, M. Lau and T.J. Fitch, 1997. Curing kinetics and thermal properties of vinyl ester resins. J. Applied Polymer Sci., 64: 769-781. DOI: 10.1002/(SICI)10974628(19970425)64:4<769::AID-APP16>3.0.CO;2-P

Fowler, D.W., 1989. Future trends in polymer concrete, Polymers in Concrete: Advances and Applications. ACI SP-116: 129-143.

Haddad, M.U., D.W. Fowler and D.R. Paul, 1983. Factors affecting the curing and strength of polymer concrete. J. Am. Concrete Institute, 80: 396-402.

Hyun, S.H. and J.H. Yeon, 2012. Strength development characteristics of UP-MMA based polymer concrete with different curing temperature. Construction Building Materials, 37: 387-397.

DOI: 10.1016/j.conbuildmat.2012.07.094

Ohama, Y., 1973. Mix proportions and properties of polyester resin concretes, Polymers in Concrete, SP40, American Concrete Institute, pp: 283-294.

Ohama, Y., 1978. Determination Methods for Working Life of Polyester Resin Concrete, Polymers in Concrete, American Concrete Institute, SP 58-3, pp: 31-40.

Son, S.W. and J.H. Yeon, 2012. Mechanical properties of acrylic polymer concrete containing methacrylic acid as an additive. Construction Building Materials, 37: 669-679.

DOI: $10.1016 /$ j.conbuildmat.2012.07.093

Yeon, J.H. and S.H Hyun, 2012. Effects of temperature and binder components on working life of fresh MMA modified UP polymer concrete. In. J. Highway Eng., 14: 51-61.

DOI: 10.7855/IJHE.2012.14.4.051

Yeon, K.S., J.Y. Cha and J.H. Yeon, 2015. Effects of DMT and TMPTMA on working life of acrylic polymer concrete exposed to low curing temperature. Polymers, 7: 1587-1598.

DOI: $10.3390 /$ polym 7091472 